\title{
Anion Currents and Predicted Glutamate Flux through a Neuronal Glutamate Transporter
}

\author{
Thomas S. Otis and Craig E. Jahr \\ Vollum Institute, Oregon Health Sciences University, Portland, Oregon 97201
}

Kinetic properties of a native, neuronal glutamate transporter were studied by using rapid applications of glutamate to outside-out patches excised from Purkinje neurons. Pulses of glutamate activated anion currents associated with the transporter that were weakly antagonized by the transporter antagonist kainate. In addition, kainate blocked a resting anion conductance observed in the absence of glutamate. Transporter currents in response to glutamate concentration jumps under a variety of conditions were used to construct a cyclic kinetic model of the transporter. The model simulates both the anion conductance and the glutamate flux through the transporter, thereby permitting several predictions regarding the dynamics of glutamate transport at the synapse. For example, the concentration-dependent binding rate of glutamate to the transporter is high, similar to binding rates suggested for ligand-gated glutamate receptors. At saturating glutamate concentrations, transporters cycle at a steady-state rate of $13 / \mathrm{sec}$. Transporters are predicted to have a high efficiency; once bound, a glutamate molecule is more likely to be transported than to unbind. Physiological concentrations of internal sodium and glutamate significantly slow net transport. Finally, a fixed proportion of anion and glutamate flux is expected over a wide range of circumstances, providing theoretical support for using net charge flux to estimate the amount and time course of glutamate transport.

Key words: EAAT4; climbing fiber; EPSC; uptake; cerebellum; anion conductance
Removal of neurotransmitter by glutamate transporters is required for the normal function of central excitatory synapses. Transgenic mice lacking a widely expressed glial glutamate transporter have a seizure disorder, enhanced susceptibility to brain injury, and a shortened lifespan (Tanaka et al., 1997b). Impairment of glutamate transport also may play a role in the neurodegenerative disease amyotrophic lateral sclerosis (Lin et al., 1998).

Improved understanding of glutamate transporters could provide insight into their function during normal and pathophysiological excitation. For instance, how rapidly does glutamate bind to transporters? Given binding, what is the probability that a glutamate molecule will be transported? On what time scale does translocation occur? How long is a complete cycle of transport? Answers to these questions would permit better predictions of the spatial and temporal extent of glutamate excitation and the roles of transporters in sculpting excitatory signals.

Glutamate transport is driven by stoichiometric coupling to cotransport of sodium (Stallcup et al., 1979), countertransport of potassium (Kanner and Sharon, 1978), and the movement of a pH-changing ion (Bouvier et al., 1992; Zerangue and Kavanaugh, 1996). Proposed stoichiometries predict that each transport cycle results in the translocation of one or two positive charges with each glutamate molecule. However, anion conductances $\left(\mathrm{G}_{\mathrm{TA}} \mathrm{s}\right)$ also are associated with the activation of recombinant (Fairman

\footnotetext{
Received May 14, 1998; revised June 22, 1998; accepted June 24, 1998.

This project was supported by National Institutes of Health Grant NS21419. We are grateful to J. Dzubay and W. Fairman and to Drs. D. Bergles, J. Diamond, M. Kavanaugh, M. Sonders, and J. Wadiche for helpful comments on this manuscript. In addition, Drs. M. Kavanaugh and J. Wadiche provided invaluable assistance and open discussions at all stages during this work.

Correspondence should be addressed to Dr. Thomas S. Otis, Department of Neurobiology, UCLA Medical Center, 10833 Le Conte Avenue, Box 951763, Los Angeles, CA 90095-1763. E-mail: otist@ucla.edu.

Copyright (ㄷ) 1998 Society for Neuroscience $0270-6474 / 98 / 187099-12 \$ 05.00 / 0$
}

et al., 1995; Wadiche et al., 1995a) and native (Billups et al., 1996; Eliasof and Jahr, 1996; Takahashi et al., 1996; Otis et al., 1997) transporters. Furthermore, anion flux is not linked stoichiometrically to glutamate transport. The transport rate does not depend on anion concentrations, and transport occurs in the absence of permeant anions (Fairman et al., 1995; Wadiche et al., 1995a). Under conditions in which no net transport is expected, $\mathrm{G}_{\mathrm{TA}}$ is still observed (Billups et al., 1996). These data support the proposal that anions pass through glutamate transporters down their electrochemical gradient as if anions were passing through a glutamate-gated channel.

Two of the five characterized glutamate transporters, excitatory amino acid carrier 1 (EAAC1) (Kanai and Hediger, 1992) and excitatory amino acid transporter 4 (EAAT4), have been reported to be expressed in Purkinje neurons (Kanai et al., 1995; Furuta et al., 1997; Dehnes et al., 1998) (but see Tanaka et al., 1997a). $G_{\text {TA }}$ can be detected upon activation of climbing fiber synaptic inputs and elicited in membrane patches by glutamate application (Otis et al., 1997). The fraction of synaptic transporter current attributable to EAAT3 versus EAAT4 is unknown. However, patch currents and synaptic responses are observed only when internal $\mathrm{NO}_{3}{ }^{-}$or $\mathrm{SCN}^{-}$is present, indicating that the Purkinje neuron transporter current is predominated by $G_{T A}$. Because EAAT4 has a much larger fractional $G_{\text {TA }}$ than does EAAC1 (Fairman et al., 1995; Wadiche et al., 1995a), we suggest that the responses in this study are attributable primarily to EAAT4.

A major aim of this study is to use measurements of $\mathrm{G}_{\mathrm{TA}}$ to develop a kinetic model linking the gating of $\mathrm{G}_{\mathrm{TA}}$ to the binding and translocation of substrate and coupled ions. This model can be used to interpret synaptic transporter currents and predict the amount and time course of glutamate uptake during synaptic transmission. 


\begin{tabular}{|c|c|c|c|c|}
\hline $\begin{array}{l}\text { Pipette contents } \\
\text { (in } \mathrm{mM} \text { ): }\end{array}$ & $\begin{array}{l}140 \mathrm{KSCN}, \\
0 \text { glutamate }\end{array}$ & $\begin{array}{l}130 \mathrm{KSCN}, \\
10 \text { K-glutamate }\end{array}$ & $\begin{array}{l}135 \mathrm{KSCN} \text {, } \\
5 \text { NaSCN, } \\
5 \text { Na-glutamate }\end{array}$ & $\begin{array}{l}130 \text { NaSCN, } \\
10 \text { Na-glutamate }\end{array}$ \\
\hline Brief pulse, $\tau$ (msec) & $\begin{array}{l}8.6 \pm 0.5(21) \\
9.6\end{array}$ & $\begin{array}{l}12.8 \pm 3(3) \\
9.6\end{array}$ & $\begin{array}{l}22 \pm 5.3(4)^{*} \\
19.6\end{array}$ & $\begin{array}{l}54 \pm 12(2)^{*} \\
\mathbf{4 7 . 8}\end{array}$ \\
\hline Long pulse, $\tau$ (msec) & $\begin{array}{l}9.4 \pm 0.5(28) \\
\mathbf{1 1 . 9}\end{array}$ & $\begin{array}{l}13.2 \pm 1.4(5)^{*} \\
\mathbf{1 2 . 1}\end{array}$ & $\begin{array}{l}11 \pm 0.6(4) \\
9.2\end{array}$ & $\begin{array}{l}12 \pm 1.9(6) \\
\mathbf{5 . 1}\end{array}$ \\
\hline$I_{\mathrm{ss}} / I_{\mathrm{PEAK}}(\%)$ & $\begin{array}{l}13.5 \pm 2(29) \\
\mathbf{1 1 . 3}\end{array}$ & $\begin{array}{l}11 \pm 3(5) \\
9.5\end{array}$ & $\begin{array}{l}31 \pm 5(4)^{*} \\
\mathbf{3 5}\end{array}$ & $\begin{array}{l}78 \pm 4(10)^{*} \\
\mathbf{7 1 . 5}\end{array}$ \\
\hline
\end{tabular}

The decay of responses to brief pulses was best described by two exponential components in the $135 \mathrm{KSCN}, 5 \mathrm{Na}-\mathrm{SCN}, 5$ Na-glutamate and in the $130 \mathrm{Na}-\mathrm{SCN}, 10 \mathrm{Na}$-glutamate conditions. The time constants reported are of the form $\tau=A_{1} \times$ $\tau_{1}+A_{2} \times \tau_{2}$, where $A_{1}$ and $A_{2}$ are the fractions of the decay contributed by each time constant. Bold values are from identical analysis of simulations generated by the model in Figure 6. An asterisk denotes a significant difference at a level of $p<0.05$ from the $140 \mathrm{KSCN}, 0$ glutamate condition.

\section{MATERIALS AND METHODS}

Brain slice preparation. Outside-out patches were removed from Purkinje neurons in standard $300-\mu \mathrm{M}$-thick parasagittal slices of rat cerebellum. Techniques for making brain slices were similar to those described previously (Otis et al., 1997). Slices were prepared by removing the brain from a 13 - to 18 -d-old rat, immersing it in ice-cold saline $\left(4^{\circ} \mathrm{C}\right)$, sectioning a block of the cerebellum to be mounted on an agar support, and using a vibratome to slice the tissue. Slices were stored for $30 \mathrm{~min}$ at $34^{\circ} \mathrm{C}$ after being sliced and thereafter were allowed to reach room temperature. Slice storage solution and the solution bathing the slice during whole-cell seal formation consisted of (in $\mathrm{mM}$ ): $119 \mathrm{NaCl}, 2.5 \mathrm{KCl}, 2.5$ $\mathrm{CaCl}_{2}, 1.3 \mathrm{MgCl}_{2}, 1 \mathrm{NaH}_{2} \mathrm{PO}_{4}, 26.2 \mathrm{NaHCO}_{3}$, and 11 glucose, saturated with $95 \% \mathrm{O}_{2} / 5 \% \mathrm{CO}_{2}$.

Outside-out patch recordings. Purkinje cells were visualized with an upright microscope with a $40 \times$ water immersion objective and equipped with infrared differential interference contrast enhancement. All recordings were made at $21-23^{\circ} \mathrm{C}$. Pipettes were pulled either from leaded glass (number 0010, World Precision Instruments, Sarasota, FL) or borosilicate glass (World Precision Instruments), and because no differences were noted in any response properties, the data have been pooled. For each experiment one of four different pipette solutions was used, containing (in mM) (1) $140 \mathrm{KSCN}$; (2) $130 \mathrm{KSCN}, 10$ glutamate, $\mathrm{K}^{+}$-salt; (3) $135 \mathrm{KSCN}, 5 \mathrm{NaSCN}, 5$ glutamate, $\mathrm{Na}^{+}$-salt; or (4) $130 \mathrm{NaSCN}, 10$ glutamate, $\mathrm{Na}^{+}$-salt. All solutions also contained (in mM): 10 HEPES, 10 EGTA, and $1 \mathrm{MgCl}_{2}$ and were adjusted to $\mathrm{pH} 7.3$ with either $\mathrm{KOH}$ or $\mathrm{NaOH}$ as appropriate. Patches were excised from the cell body and initial segment of the proximal dendrite and positioned in front of one barrel of a two-barreled application pipette. The application pipette was shaped from $\theta$ glass tubing by heating and pulling the tubing such that each barrel had an internal diameter of $\sim 80 \mu \mathrm{m}$. The application pipette was attached to a piezoelectric bimorph, allowing for rapid translation of the tip over distances of $40-80 \mu \mathrm{m}$. A short segment of tubing (PE-10) was fed into the back of each barrel of the application pipette and was connected to a four-way manifold. When a patch was in position, three of the gravity-fed inputs to this manifold were clipped off, and a fourth was left open so that solutions continuously flowed from the tip of the application pipette at all times while a patch was present. To switch solutions, we first positioned the patch in front of a flowing barrel, and we switched the input line to the other barrel by clipping and unclipping lines. Using this approach, we typically achieved steady concentrations in 2-3 min. In the dose versus peak response experiments of Figure 4, a 2 $\mathrm{mM}$ dose was delivered to each patch, other doses were tested, and then the $2 \mathrm{~mm}$ dose was presented again. Data were included in the analysis only if the response recovered to within $\pm 10 \%$ of the peak amplitude measured during the first application. At the end of each experiment the recording pipette tip was cleared with positive pressure, and a solution of reduced ionic strength (diluted 50\%) was allowed to flow through the glutamate-containing barrel. In this way the same jumps of the application pipette as were elicited during the experiment could be delivered, and the change in holding current could be recorded. These "open-tip" currents are displayed above each set of experimental traces and represent the time course of solution exchange across the tip of the pipette. In practice the actual solution exchange at the patch surface may be somewhat slower. For the majority of experiments the solutions perfusing the patches contained (in mM): $140 \mathrm{NaCl}, 1.8 \mathrm{CaCl}_{2}, 1 \mathrm{MgCl}_{2}, 5 \mathrm{HEPES}$,
0.1 picrotoxin, $0.0125 \mathrm{NBQX}$, and 0.025 GYKI 52466, adjusted to $\mathrm{pH} 7.4$ with $\mathrm{NaOH}$. A few of the initial experiments contained $5.4 \mathrm{mM} \mathrm{KCl}$ substituted for some $\mathrm{NaCl}$, and the results were not significantly different, so the data have been pooled. Currents were recorded with an Axopatch $1 \mathrm{C}$ amplifier (Axon Instruments, Foster City, CA), filtered at $1-2 \mathrm{kHz}$, and digitized at $10 \mathrm{kHz}$. All salts, glutamate, $\mathrm{D}$-aspartate, and picrotoxin were purchased from Sigma (St. Louis, MO). NBQX and GYKI 52466 were purchased from Research Biochemicals (Natick, MA).

Data analysis. Data analysis, including exponential fitting and fitting of the Hill equation to dose-response relationships was performed in Origin 4.0 (MicroCal, Northampton, MA). For some traces an average trace taken with the patch moved out of the flow was subtracted to remove artifacts attributable to the voltage pulse applied to the bimorph. Alternatively, decaying single exponentials fit to such records were subtracted. Time 0 for exponential fits was fixed at the time of the pulse onset, and the fits were forced to the appropriate steady-state current level (amplitude measured at the end of the $100 \mathrm{msec}$ pulse for long-pulse data in Table 1; zero for the short pulses). Error bars represent \pm 1 SEM. Student's $t$ test was used to determine confidence intervals.

Simulations. Simulations were performed by using the Simulation Control Program (Simulation Resources, Berrien Springs, MI). The model was optimized by varying the rates until a given set of rates described the major features of the data. Typically, the evaluation of a given version of the model involved comparing simulations to idealized data traces with average kinetic properties. The model was optimized by comparing it with features of the experimental data in the following order: (1) the kinetics of responses to brief and long pulses with no internal $\mathrm{Na}^{+}$or glutamate, $(2)$ the internal sodium and glutamate dependence of these responses, (3) the recovery time course elicited with pairs of pulses, and (4) the dose dependence of the peak and rise times. When the rates providing an acceptable fit to these parameters were determined, a small adjustment was made to the rates so that the model would conform to the thermodynamic equation relating the ion and glutamate gradients to the membrane potential. With all ion gradients set to one, zero flux should occur in a glutamate gradient determined by the simplified equation relating membrane potential, $\Psi$, to the glutamate Nernst potential:

$$
\Psi=-(R T / 2 F) \ln \left(\left[\mathrm{Glu}_{\mathrm{i}}\right] /\left[\mathrm{Glu}_{0}\right]\right),
$$

where $R$ is the gas constant, $T$ is the temperature, and $F$ is Faraday's constant. Given that the $\Psi$ for the model was approximately $-85 \mathrm{mV}$ (mean holding potential $=-83 \pm 1.6 \mathrm{mV} ; n=67$ patches) for these experiments, the glutamate gradient at equilibrium should be 853 -fold. With all $\mathrm{Na}^{+}$and $\mathrm{K}^{+}$concentrations set to $80 \mathrm{mM}$ and $\mathrm{pH}_{\mathrm{i}}=\mathrm{pH}_{\mathrm{o}}=7.3$, rates in the model were adjusted such that zero net flux occurred with $\left[\mathrm{Glu}_{\mathrm{i}}\right] /\left[\mathrm{Glu}_{\mathrm{o}}\right]=853$.

\section{RESULTS}

Anion currents associated with native (Bergles and Jahr, 1997; Otis et al., 1997) and recombinant (Wadiche and Kavanaugh, 1998) glutamate transporters can be recorded in outside-out membrane patches in response to glutamate transporter substrates. By rapidly applying substrates to patches, we can achieve 
A

$140 \mathrm{mM}\left[\mathrm{K}^{+}\right]_{\mathrm{in}} / 0 \mathrm{mM}[\text { glutamate }]_{\mathrm{in}}$

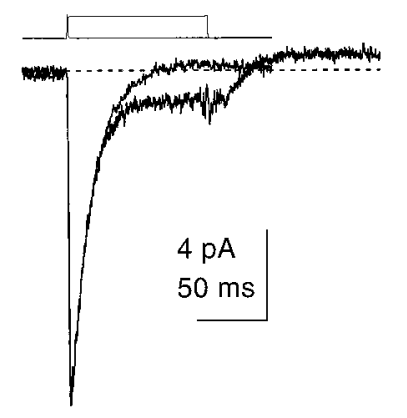

C
B

$140 \mathrm{mM}\left[\mathrm{K}^{+}\right]_{\text {in }} / 10 \mathrm{mM}$ [glutamate $_{\text {in }}$

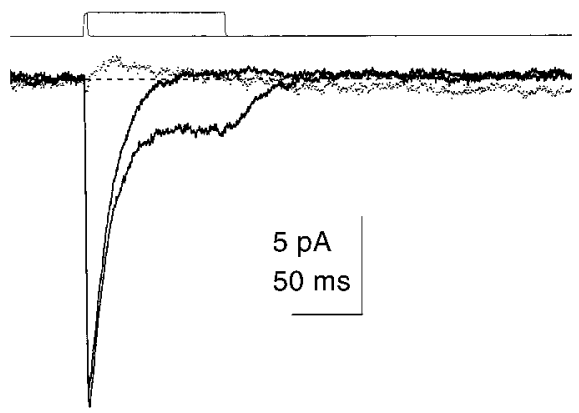

D

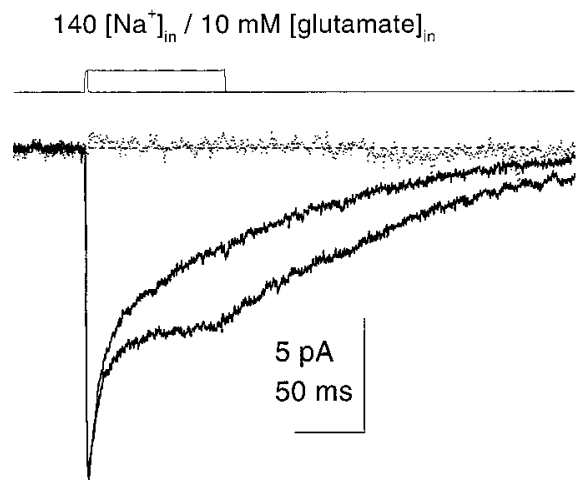

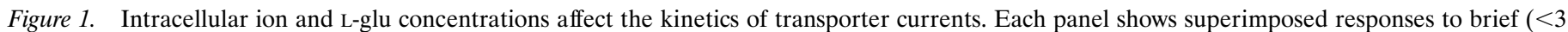

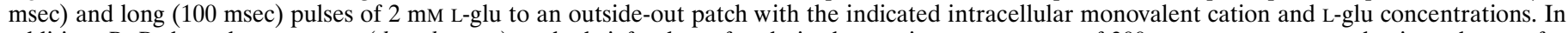

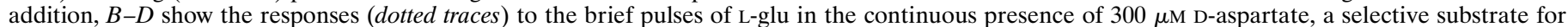

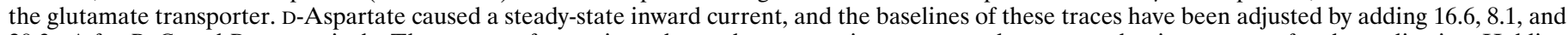

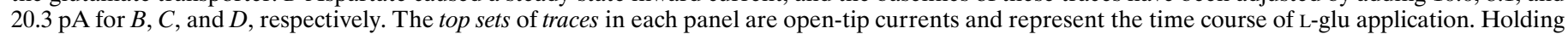
potential $\left(V_{\mathrm{h}}\right)$ is $-69,-85,-78$, or $-88 \mathrm{mV}$ for $A-D$, respectively. Each trace is the average of $4-12$ responses.

precise temporal control of the concentrations of substrates and ions involved in transport. In addition, different ion and substrate concentrations can be imposed on the cytoplasmic side of the transporter. In all of the experiments in the present study, transporter currents were isolated from ligand-gated receptor currents by continuously exposing the patches to a cocktail of receptor antagonists, including glutamate receptor antagonists NBQX $(12.5 \mu \mathrm{M})$ and GYKI $52466(50 \mu \mathrm{M})$ and the $\mathrm{GABA}_{\mathrm{A}}$ receptor antagonist picrotoxin $(100 \mu \mathrm{M})$. Consistent with previous reports for Purkinje neurons (Haüsser and Roth, 1997), initial experiments performed with $50 \mu \mathrm{M}$ D-APV gave no indication that NMDA receptors were present; thereafter, APV was not included.

The kinetics of transporter anion currents are sensitive to internal cation concentrations

Studies by Barbour et al. (1991) of the glutamate transporter in Müller glial cells suggested that internal glutamate (L-glu) inhibits the transporter current but only if internal $\mathrm{Na}^{+}$is also present. We first tested whether the $\mathrm{G}_{\mathrm{TA}}$ of the Purkinje neuron transporter showed a similar dependence on internal $\mathrm{Na}^{+}$and L-glu and, if so, how these internal species affected the kinetics of anion currents. Figure 1 illustrates responses to brief-duration $(<3$ $\mathrm{msec})$ and long-duration $(100 \mathrm{msec})$ pulses of millimolar concentrations of L-glu, with internal solutions containing differing amounts of L-glu and $\mathrm{Na}^{+}$as indicated. The time course of solution exchange in this and all subsequent figures is illustrated by the top set of traces in each panel, which represent the open-tip currents recorded as described in Materials and Methods. As expected for glutamate transporter currents, responses to brief pulses of L-glu were abolished by application of the glutamate transporter agonist D-aspartate $(300 \mu \mathrm{M}$; dotted traces in Fig. $1 B-D)$, which caused an inward current shift (baselines of displayed traces have been adjusted, as indicated in the legend). Transporter anion currents were seen despite the inclusion of millimolar concentrations of L-glu in the pipette (Fig. $1 B$ ), and the addition of $10 \mathrm{~mm}$ L-glu to the $\mathrm{K}^{+}$-containing internal solution had no effect on the kinetics of the responses nor on the size of steady-state currents relative to the peak currents elicited by 100 msec pulses (Fig. 1A,B, Table 1). By contrast, adding millimolar concentrations of $\mathrm{Na}^{+}$and L-glu to the pipette solution significantly increased the relative size of the steady-state current and slowed the decay in response to brief pulses by introducing a slow exponential component (Fig. 1C, Table 1). Under conditions in which no $\mathrm{K}^{+}$is present and high concentrations of $\mathrm{Na}^{+}$and L-glu exist inside and outside, transporters are expected to operate as homoexchangers, i.e., with no net flux of L-glu or $\mathrm{Na}^{+}$ (Kanner and Sharon, 1978; Kanner and Bendahan, 1982; Kavanaugh et al., 1997). As shown in Figure $1 D$ and Table 1, such conditions caused the anion currents to slow still further and the relative size of the steady-state currents to grow larger. Compar- 


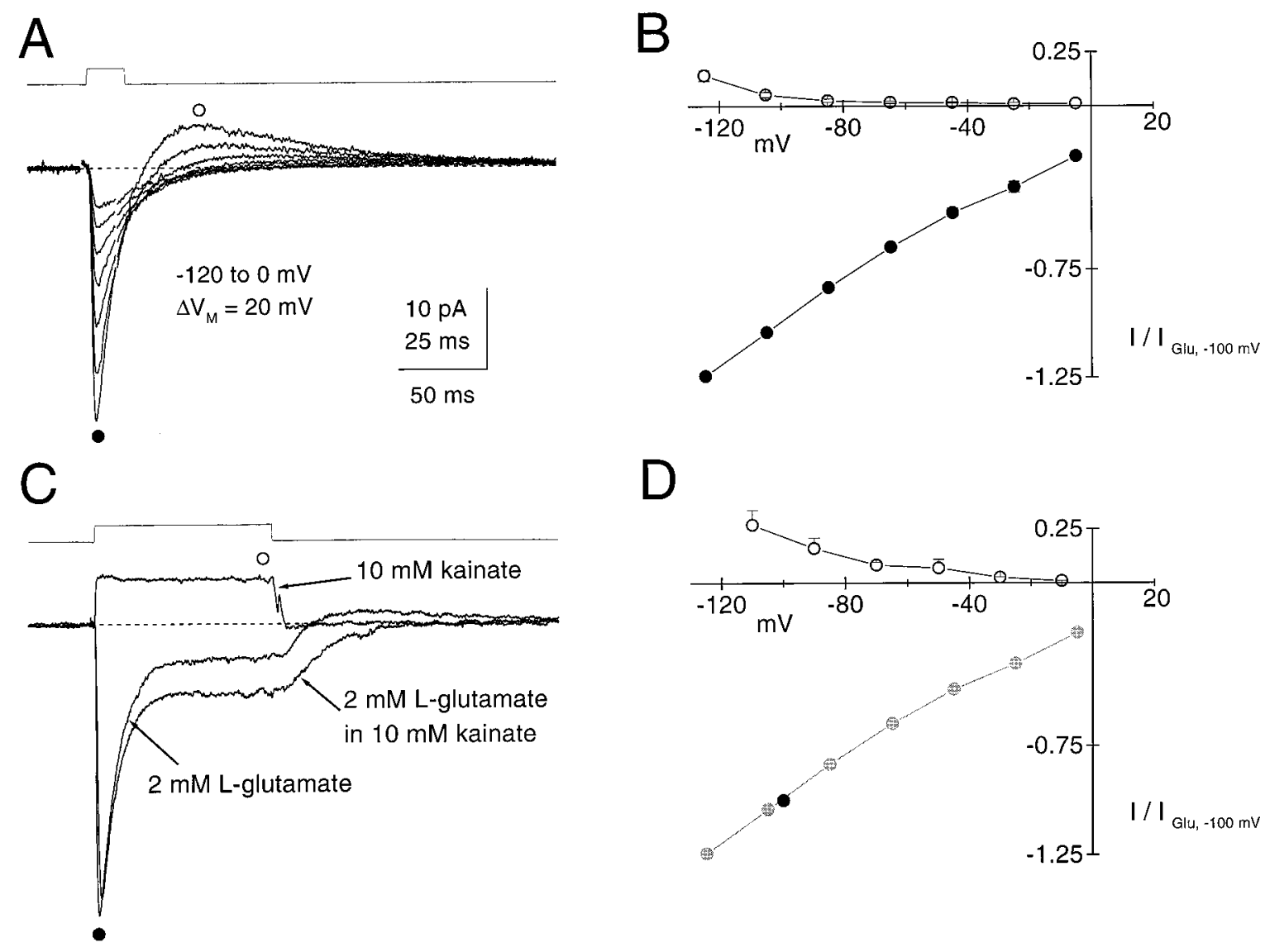

Figure 2. Transporter current can be detected in the absence of L-glu. $A$, Responses elicited by $10 \mathrm{msec}, 2 \mathrm{~mm}$ pulses of L-glu at different membrane potentials between -120 and $0 \mathrm{mV}$. At hyperpolarized potentials the current decays past the initial baseline and transiently appears outward (at approximately the time marked by the $\bigcirc$ ). This phase is termed the "overshoot current." $B$, The mean inward $(\bullet)$ and outward $(O)$ peak amplitudes of responses in four similar experiments were measured and are plotted as a function of membrane potential. All measurements were normalized in each patch to the peak inward current at $-100 \mathrm{mV}$. C, The transporter antagonist kainate inhibits inward current in the absence of L-glu and weakly inhibits the response to $2 \mathrm{mM} \mathrm{L-glu}$. From the same patch, responses to 100-msec-duration jumps into $10 \mathrm{~mm}$ kainate, $2 \mathrm{~mm}$ L-glu, or $2 \mathrm{~mm}$ L-glu in the continuous presence of $10 \mathrm{~mm}$ kainate are superimposed. $V_{\mathrm{h}}=-95 \mathrm{mV}$. The scale bar is as in $A$, but with a 50 msec time base. $D$, The peak amplitude of the inward current $(-)$ in response to $2 \mathrm{mM} \mathrm{L}$-glu and the average amplitude of the steady-state current (at $\bigcirc)$ in response to $10 \mathrm{~mm}$ kainate were measured in six patches. The kainate-elicited current was measured at different membrane potentials, and for each patch all values were normalized to the peak inward current at $-100 \mathrm{mV}$. The $I-V$ curve for the inward current in $B$ has been superimposed ( gray circles) for comparison over the entire range of membrane potentials. The current versus voltage relationships in $B$ and $D$ are consistent with the outward current resulting from a block of an inward current with the same ionic basis as that elicited by L-glu.

ing the data from experiments like those in Figure 1, $B$ and $C$, suggests that, after translocation to the inside, at least one $\mathrm{Na}^{+}$ must unbind before L-glu dissociates. In addition, the data imply that Purkinje neuron transporters conduct anions despite having no net movement of L-glu or coupled charges (Billups et al., 1996). Finally, these results provide further evidence that the anion currents arise from the transporter, because changes in the internal $\left[\mathrm{Na}^{+}\right]$and [L-glu] should alter transport, but not receptor-mediated events.

\section{An anion leak current is present in the absence of glutamate}

Transporters for several different neurotransmitters exhibit constitutive leak conductances in the absence of substrates (Cammack et al., 1994; Mager et al., 1994; Galli et al., 1995; Vandenberg et al., 1995; Bergles and Jahr, 1997; Sonders et al., 1997). For the Purkinje neuron transporter, evidence for an anion leak conductance in the absence of L-glu is shown in Figures 2 and 3. The decay of the inward current in response to brief exposure to 2 mM L-glu (2-10 msec) showed an overshoot that was especially prominent at hyperpolarized potentials. Relative to the baseline before the L-glu pulse, this outward phase of the current was apparent between 20 and $100 \mathrm{msec}$ after the initial inward peak current (Fig. $2 A$, open circle). The ionic dependence of the inward (filled circle) and outward (open circle) phases of such responses was examined by making $2 \mathrm{~mm} \mathrm{L-glu} \mathrm{jumps} \mathrm{of} 10 \mathrm{msec}$ duration at different membrane potentials between -130 and $0 \mathrm{mV}$. Results from a single patch are shown in Figure $2 A$ and average data for six patches in Figure $2 B$. As expected for an internal solution containing $\mathrm{SCN}^{-}$, an anion with high permeability through the glutamate transporter (Eliasof and Jahr, 1996; Otis et al., 1997), the current-voltage $(I-V)$ relationship for the initial peak was inward at all membrane potentials and had an extrapolated reversal potential greater than $+30 \mathrm{mV}$. The peak of the overshoot measured after the end of the L-glu pulse was outward at all potentials and showed an $I-V$ relationship with a similar, although slightly more rectifying, shape (Fig. $2 B$ ). These $I-V$ relationships are consistent with the idea that the two phases have the same ionic basis and that the later outward phase results from a 
A
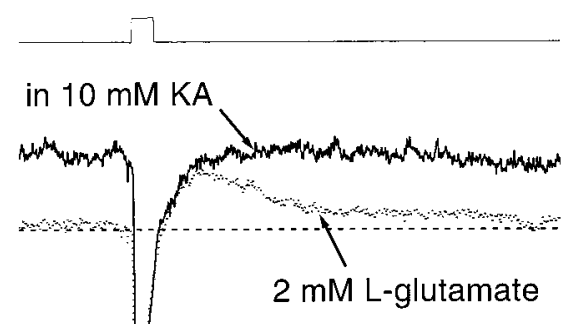

$$
\begin{aligned}
& 3 \mathrm{pA} \\
& 50 \mathrm{~ms}
\end{aligned}
$$

B

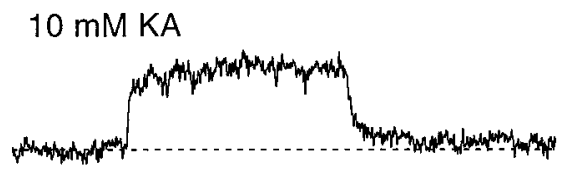

Figure 3. Kainate blocks the overshoot current. $A$, Responses to a $10 \mathrm{msec}$ pulse of $2 \mathrm{mM} \mathrm{L-glu}$ in the continuous presence (bold trace) or absence (dotted trace) of 10 mm kainate. Note that the baseline of the trace in the continuous presence of kainate has shifted outward and that the overshoot current has been blocked. $B$, A 100 -msec-duration jump into $10 \mathrm{~mm}$ kainate elicits an outward current in the same patch. $V_{\mathrm{h}}=-126 \mathrm{mV}$. transient reduction in a tonic conductance. The reduction in tonic conductance is elicited only on rapid L-glu binding, and the model presented later suggests that this may be caused by synchronous activation and movement of transporters through conducting states to a series of nonconducting states in a cycle.

Kainate and dihydrokainate, conformationally restricted analogs of L-glu, competitively bind to the GLT-1 glutamate transporter but, unlike most competitive ligands, are not transported (Arriza et al., 1994; Vandenberg et al., 1995; Wadiche et al., 1995b). As expected if EAAT4 or EAAC1 transporters were present in the patches, high concentrations of kainate only weakly antagonized responses to 2 mm L-glu (Arriza et al., 1994; Fairman et al., 1995). In 10 patches the mean percentage of the peak inward current elicited by $2 \mathrm{~mm}$ L-glu in the continuous presence of $10 \mathrm{~mm}$ kainate to that in the absence of kainate was $104 \pm 6 \%$ (Fig. 2C). However, in outside-out patches that exhibited large inward currents in response to L-glu (peak $>10 \mathrm{pA}$ ), jumps into $10 \mathrm{~mm}$ concentrations of kainate $(n=14)$ or dihydrokainate $(n=$ 2 ) elicited outward currents (Figs. $2 C, 3 B$ ). The mean $I-V$ relationship for these kainate-elicited outward currents (Fig. 2D) was similar in shape to the $I-V$ relationship for the overshoot shown in Figure $2 B$, although at all potentials the kainate-sensitive current was relatively larger than the overshoot. In four patches the outward current in kainate was $18 \pm 6 \%$ of the peak inward current elicited by L-glu at $-90 \mathrm{mV}$. These observations suggest, first, that the transporters mediate a tonic anion current in the absence of substrate (Bergles and Jahr, 1997); second, that this current is transiently inhibited after brief exposure to L-glu; and, third, that the same current can be blocked by the nontransported antagonist kainate.

If the overshoot current and the kainate-sensitive current are both the result of blocking a tonic leak conductance, then kainate should block the overshoot. Figure $3 A$ shows this to be the case; a $10 \mathrm{msec}$ pulse of $2 \mathrm{~mm}$ L-glu activated a fast inward current, followed by a large overshoot current, and the overshoot was abolished in $10 \mathrm{~mm}$ kainate. Figure $3 B$ illustrates the response in the same patch to a 100 -msec-duration jump into $10 \mathrm{~mm}$ kainate. The result in Figure $3 A$ was observed in five patches with a prominent, late outward phase after the L-glu jump. These experiments support the proposal that a substrate-independent anion leak exists and that the leak can be inhibited by substrate or antagonist binding.

\section{Glutamate dose dependence of the transporter currents}

To estimate how rapidly L-glu binds to the transporter, we delivered jumps into different concentrations of L-glu to individual patches. This was accomplished by using a manifold input to the two-barrel application pipette (see Materials and Methods) so that each patch could be exposed to up to four different concentrations. Figure $4 A$ shows data from a typical patch. Responses to 50-msec-duration jumps into the indicated concentrations have been superimposed, clearly showing that the rise time and the peak amplitude vary with different concentrations of L-glu. Average data from several patches are shown in Figure 4, $B$ and $C$. Each patch included in the analysis was exposed to $2 \mathrm{~mm} \mathrm{L-glu}$ and at least two additional concentrations; the symbols represent measurements from 3 to 16 patches. The superimposed lines were obtained from simulations performed with the model presented later in Results. Fits of the Hill equation to the dose versus normalized peak current relationship in Figure $4 B$ yielded a $K_{\mathrm{D}}$ of $30 \mu \mathrm{M}$ and a Hill coefficient of 1 .

\section{Time course of recovery from depression}

As indicated by the experiments summarized in Table 1, the transporter current depresses during sustained applications of L-glu to a level $\sim 10-15 \%$ of the peak current amplitude. One simple interpretation of these data and the rapid activation of the conductance at high doses (Fig. 4) is that the binding of glutamate activates an anion-conducting state with little delay but that this state is visited less frequently because it is inaccessible at later times during a complete cycle of transport. If this hypothesis is correct, the rate of recovery of the anion current from this depression may reflect the cycling rate of the transporters. The recovery rate can be measured by delivering pairs of pulses of L-glu separated by varying intervals. Data from such an experiment are displayed in Figure $5 A$; mean data for six patches are displayed in Figure $5 B$. The line shows the results from simulated responses from the model presented below. The recovery can be well described by a single exponential of $60 \mathrm{msec}$ starting after the $10 \mathrm{msec}$ interval, and, following the reasoning given above, this would correspond to a maximal cycling rate of $\sim 14 \mathrm{~Hz}$.

\section{A kinetic model of the Purkinje cell glutamate transporter}

The data presented above were used to develop a kinetic model of the Purkinje neuron transporter. Previously published models provided a starting point (Kanner and Bendahan, 1982; Wadiche et al., 1995a; Billups et al., 1996). In addition, the stoichiometry proposed for the neuronal glutamate transporter EAAT3 (EAAC1) of three $\mathrm{Na}^{+}$ions and one proton cotransported and one $\mathrm{K}^{+}$ion countertransported per L-glu molecule (Zerangue and Kavanaugh, 1997) was incorporated into the model. As illustrated in Figure 6, explicit binding of all stoichiometrically 


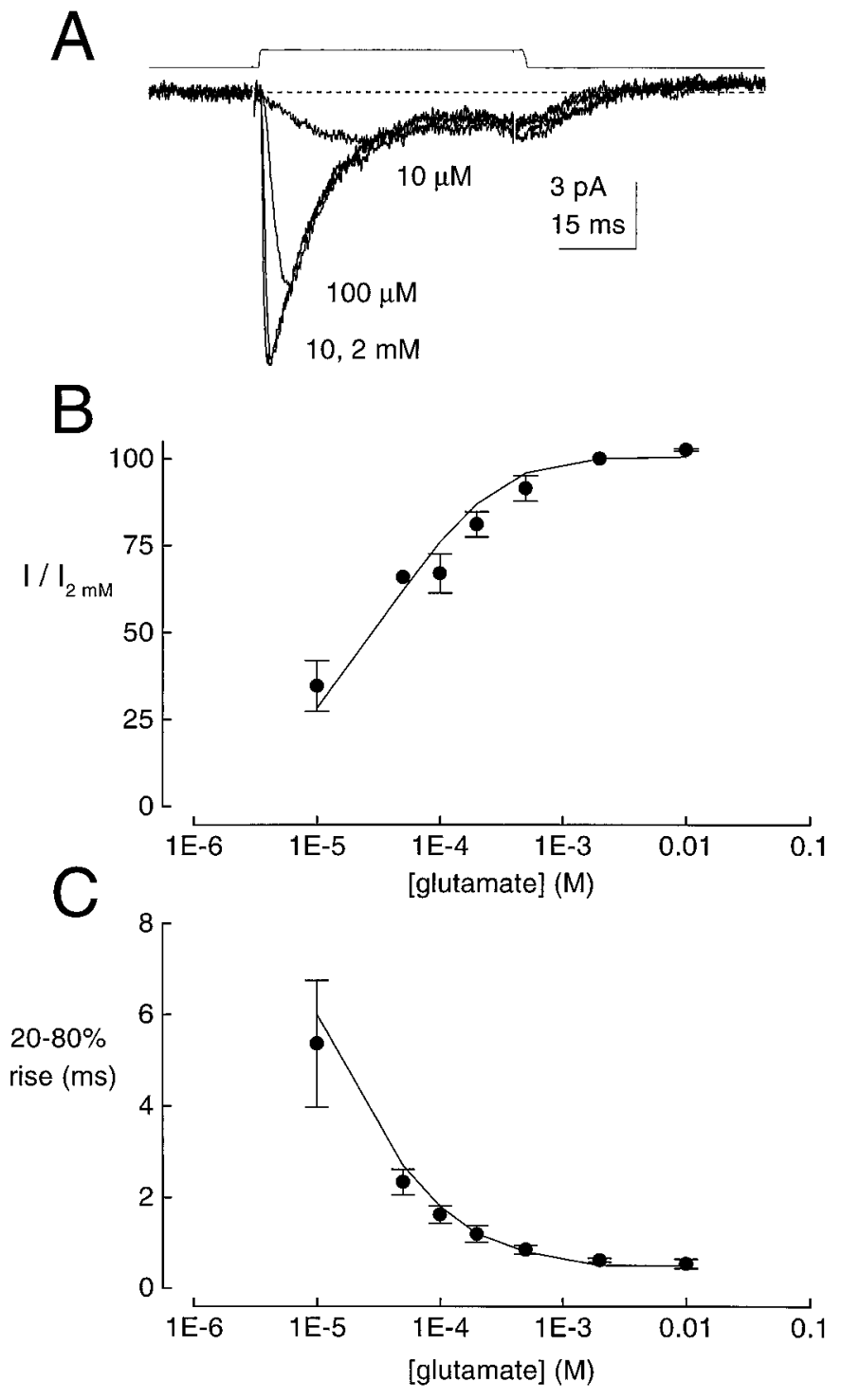

Figure 4. Dose dependencies of the rise time and peak current. $A$, Responses from the same patch to $50 \mathrm{msec}$ steps of $10000,2000,100$, and $10 \mu \mathrm{M}$ L-glu. $V_{\mathrm{h}}=-80 \mathrm{mV}$. $B$, Normalized peak amplitude versus [L-glu]. Each indicates the mean peak amplitude (normalized to the peak in response to the $2 \mathrm{~mm}$ dose) from between 3 and 11 patches. The line represents identical measurements from the simulation presented in Results. $C$, The $20-80 \%$ rise times versus [L-glu]. Patch data are represented by the ( $n=5$ to 16 patches); the line was obtained from an analysis of the simulation.

coupled ions required a cycle of 14 connected states, seven states with binding sites facing the extracellular space (subscript $o$ ) and seven states facing the intracellular space (subscript $i$ ). To introduce the details of the model, we found it useful to consider a cycle of transport. We begin with the transporter facing the extracellular space with no ions or substrate that are bound, corresponding to state $\mathrm{T}_{\mathrm{o}}$. The transporter binds three $\mathrm{Na}^{+}$ions in succession, pushing through states $\mathrm{NT}_{\mathrm{o}}, \mathrm{N}^{2} \mathrm{~T}_{\mathrm{o}}$, and into $\mathrm{N}^{3} \mathrm{~T}_{\mathrm{o}}$. At this point an L-glu molecule can bind $\left(\mathrm{GN}^{3} \mathrm{~T}_{\mathrm{o}}\right)$, followed by a proton $\left(\mathrm{HGN}^{3} \mathrm{~T}_{\mathrm{o}}\right)$; with all cotransported species bound, the transporter is able to translocate such that the binding sites now face the intracellular space $\left(\mathrm{HGN}^{3} \mathrm{~T}_{\mathrm{i}}\right)$. Into the intracellular space a $\mathrm{Na}^{+}$ion dissociates first $\left(\mathrm{HGN}^{2} \mathrm{~T}_{\mathrm{i}}\right)$ and then L-glu $\left(\mathrm{HN}^{2} \mathrm{~T}_{\mathrm{i}}\right)$, followed by the proton $\left(\mathrm{N}^{2} \mathrm{~T}_{\mathrm{i}}\right)$. Next, two $\mathrm{Na}^{+}$ions unbind in succession, causing passage through $\mathrm{NT}_{\mathrm{i}}$ to $\mathrm{T}_{\mathrm{i}}$. Finally, by binding a $\mathrm{K}^{+}$ion $\left(\mathrm{KT}_{\mathrm{i}}\right)$, the transporter can return to face the extracellular space $\left(\mathrm{KT}_{\mathrm{o}}\right)$ at which point the $\mathrm{K}^{+}$ion can dissociate.

Anion conductance is included in the model by the addition of the two states $\mathrm{N}^{3} \mathrm{~T}_{\mathrm{o}}{ }^{*}$ and $\mathrm{HGN}^{3} \mathrm{~T}_{\mathrm{o}}{ }^{*}$. The state $\mathrm{N}^{3} \mathrm{~T}_{\mathrm{o}}{ }^{*}$ is used to simulate conductance in the absence of agonist (see Figs. 2, 3). It is connected to the extracellular state bound by three $\mathrm{Na}^{+}$ions, but no $\mathrm{L}$-glu molecule $\left(\mathrm{N}^{3} \mathrm{~T}_{\mathrm{o}}\right)$. The conductance activated by L-glu is provided by $\mathrm{HGN}^{3} \mathrm{~T}_{\mathrm{o}}{ }^{*}$, connected to the first state in which the transporter has bound L-glu and all cotransported ions $\left(\mathrm{HGN}^{3} \mathrm{~T}_{\mathrm{o}}\right)$. Simulations of the $\mathrm{G}_{\mathrm{TA}}$ thus represent the sum, termed $P_{\mathrm{o}}$, of the occupancy probabilities of both conducting states.

The rate constants shown in Table 2 were determined by starting with microscopic affinities near published $K_{\mathrm{D}}$ values for the various coupled ions and then varying rates to obtain acceptable fits (see Materials and Methods). Several features of the data constrained key rates in the model. The L-glu binding rate on the outside and the opening rate for the bound open state were set by the dose dependencies of the rise times and peak current (see Fig. 4 ), whereas the rate of L-glu unbinding on the outside was controlled by the rate of decay of the current after an L-glu pulse under exchange conditions (i.e., high internal $\left[\mathrm{Na}^{+}\right]$; see Fig. $1 D$ ). The equilibrium constant describing the transition from outwardto inward-facing binding sites $\left(K_{7}\right)$ was influenced strongly by the steady-state-to-peak current ratios in L-glu. On the basis of the sensitivity of the kinetics to internal $\left[\mathrm{Na}^{+}\right]$, it was determined that a sodium ion dissociates before L-glu on the inside. The recovery rate (see Fig. 5) dictated the rate-limiting step in the cycle, the rate of unbinding of glutamate on the inside (transition $\mathrm{HGN}^{2} \mathrm{~T}_{\mathrm{i}}$ to $\mathrm{HN}^{2} \mathrm{~T}_{\mathrm{i}}$ ). This step in the cycle was chosen for the rate-limiting transition because the transporter turnover rate is known to be agonist-dependent (Fairman et al., 1995). In support of this idea, the rate of recovery measured as in Figure 5 but with pairs of D-aspartate pulses was slower than that for L-glu (T.S.O., unpublished observations). Equilibrium constants for ion binding on the outside $\left(K_{1}, K_{2}\right.$, and $\left.K_{4}\right)$ were chosen to reflect the published dose-response relationships for various ions (Barbour et al., 1991; Szatkowski et al., 1990; Fairman et al., 1995; Billups et al., 1996; Zerangue and Kavanaugh, 1996). Finally, two different binding affinities for external sodium ions were chosen to shift larger fractions of transporters toward the state to which L-glu binds $\left(\mathrm{N}^{3} \mathrm{~T}_{\mathrm{o}}\right)$ while maintaining a suitably low affinity for $\mathrm{Na}^{+}$ (Barbour et al., 1991). At steady state with no L-glu present the occupancies of the states $\mathrm{NT}_{\mathrm{o}}, \mathrm{N}^{2} \mathrm{~T}_{\mathrm{o}}$, and $\mathrm{N}^{3} \mathrm{~T}_{\mathrm{o}}$ were $0.083,0.58$, and 0.271 , respectively. The high occupancy of $\mathrm{N}^{3} \mathrm{~T}_{\mathrm{o}}$ also allowed a single unbound open state by itself to generate enough conductance in the absence of agonist (see Figs. 2, 3).

Simulations from the model matched many aspects of the experimental data. The time course of responses and the relative size of the steady-state current obtained with different internal ion and L-glu concentrations were well described, as shown in Figure 7 and in Table 1. The concentration dependencies of the peak current and $20-80 \%$ rise time were predicted accurately (Figs. $4 B, C$, lines; $8 A$ ), as was the rate of recovery of the current measured with pairs of L-glu pulses (Figs. $5 B$, line; $8 B$ ). To make comparisons with published experimental data, we obtained $K_{\mathrm{D}}$ values and Hill coefficients for fits to simulations of the steadystate current or of L-glu flux versus the concentrations of $\mathrm{Na}^{+}$, $\mathrm{H}^{+}, \mathrm{K}^{+}$, or L-glu (Table 3). These were in general agreement with published values from measurements made under similar 

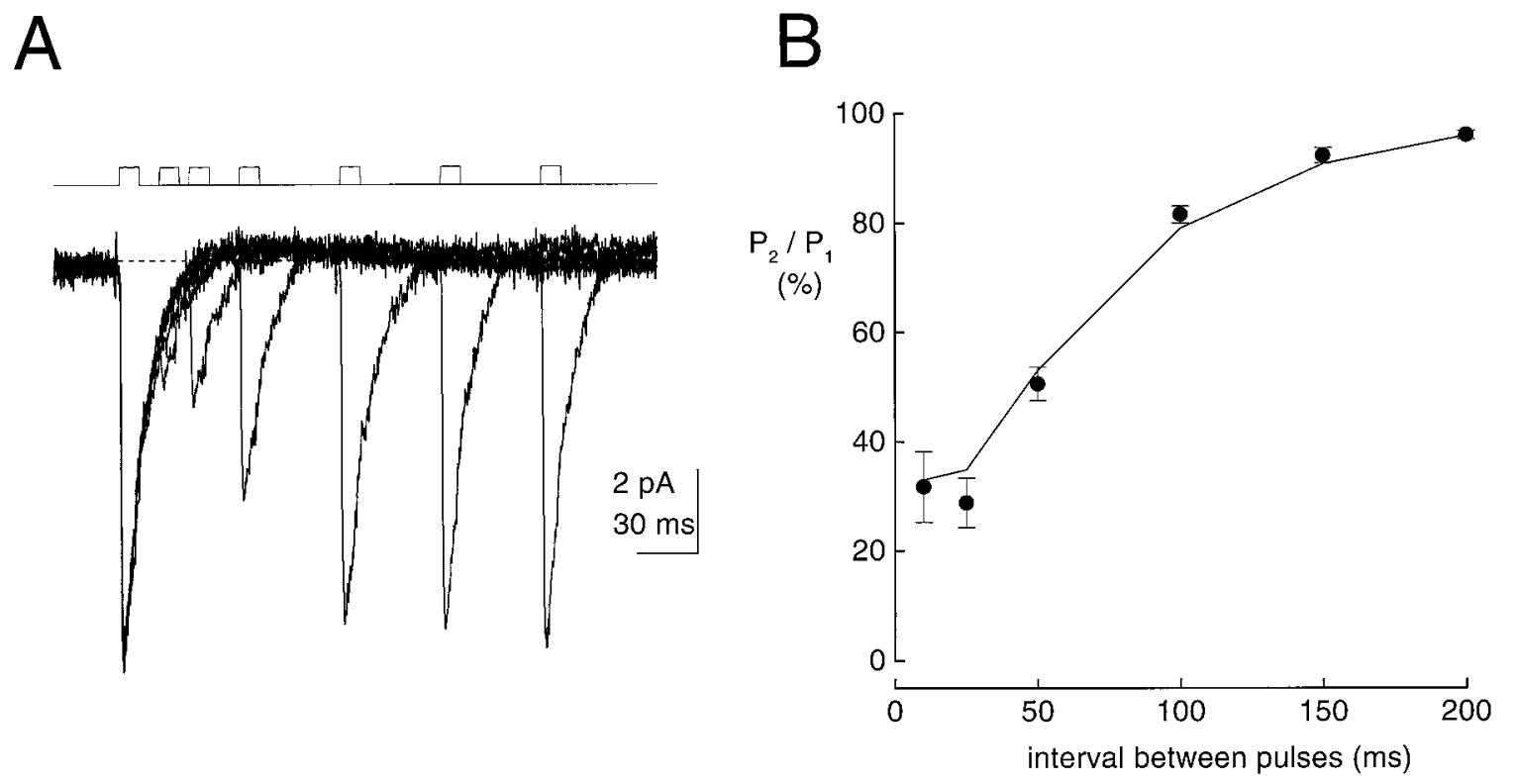

Figure 5. Recovery from depression of the transporter current. $A$, Responses to pairs of $10 \mathrm{msec}$ steps into 2 mM L-glu separated by varying intervals of $10,25,50,100,150$, and $200 \mathrm{msec} . V_{\mathrm{h}}=-74 \mathrm{mV} . B$, Depression of the peak amplitude of the second response, $P_{2}$, relative to the peak of the first, $P_{1}$, versus the interval. Mean data from six patches are represented by the $\mathbf{Q}$; the line indicates the results from an analysis of the simulation.

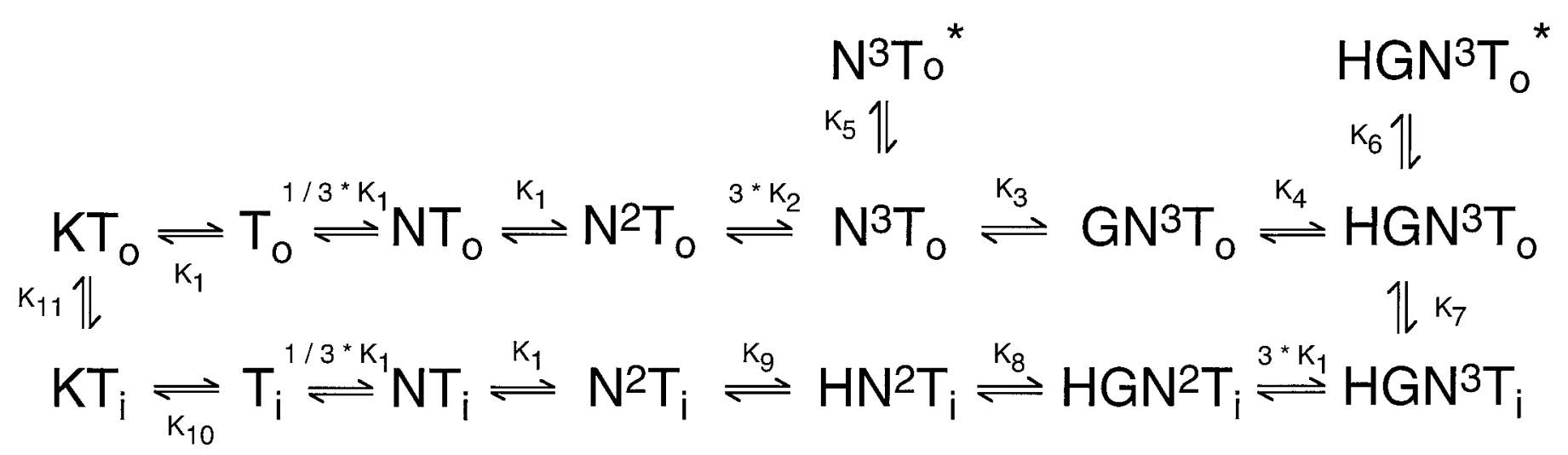

Figure 6. A kinetic model for the Purkinje neuron transporter. The subscripts $o$ and $i$ indicate whether the binding sites for L-glu or ions are facing the extracellular or intracellular spaces, respectively. The prefixes $K, N, H$, and $G$ represent bound ions $\mathrm{K}^{+}, \mathrm{Na}^{+}, \mathrm{H}^{+}$, and L-glu, whereas the superscript indicates the number of $\mathrm{Na}^{+}$ions that are bound. The asterisk denotes the two open-channel states. Equilibrium constants $K_{1}-K_{11}$ are indicated for the appropriate reactions; values for the constants are listed in Table 2.

conditions: L-glu ( $K=2.5 \mu \mathrm{M} ; n=1)$ (Fairman et al., 1995), sodium $(K=22.5 \mathrm{~mm} ; n=3)$ (Barbour et al., 1991), protons $(K=$ 26-43 nм; $n=1$ ) (Billups et al., 1996; Zerangue and Kavanaugh, 1996), or potassium ( $K=19 \mathrm{~mm} ; n=1)$ (Szatkowski et al., 1990).

The model also was able to reproduce the antagonism of the overshoot current as well as the lack of antagonism of the peak current (Fig. 8C). This was accomplished by the addition of a kainate-bound state (not shown in Fig. 6) in fast equilibrium with the state to which L-glu binds, $\mathrm{N}^{3} \mathrm{~T}_{\mathrm{o}}$. The microscopic affinity assigned to kainate binding was low (1 mM), in line with estimates for EAAT1, EAAT3, and EAAT4 (Arriza et al., 1994). Under control ionic conditions $\left(140 \mathrm{~mm}\left[\mathrm{Na}^{+}\right]_{\mathrm{o}}\right)$, simulations predicted

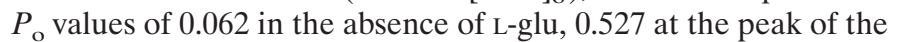
$\mathrm{L}$-glu response, and 0.114 at steady state in $\mathrm{L}$-glu. In the same ionic conditions but with $10 \mathrm{~mm}$ kainate present, these values shifted to $0.017,0.504$, and 0.114 , respectively. Thus, after subtracting the baseline $P_{\mathrm{o}}$, the peak of the simulated response in $10 \mathrm{~mm}$ kainate was $105 \%$ of the similarly determined peak in control. The small

\begin{tabular}{|c|c|c|c|}
\hline Equilibrium constant $=$ & $\begin{array}{l}\text { Backward } \\
\text { rate }(/ \text { sec }) \div\end{array}$ & $\begin{array}{l}\text { Forward } \\
\text { rate }(/ \mathrm{sec})\end{array}$ & $=K_{\mathrm{D}}$ \\
\hline$K_{1}\left(\mathrm{Na}^{+}{ }_{\text {out }} 1,2, \mathrm{~K}^{+}{ }_{\text {out }} 1\right)$ & $20 \times 10^{5}$ & $10^{8} / \mathrm{M}$ & $20 \mathrm{~mm}$ \\
\hline$K_{2}\left(\mathrm{Na}^{+}\right.$out 3$)$ & $100 \times 10^{5}$ & $10^{8} / \mathrm{M}$ & $100 \mathrm{~mm}$ \\
\hline$K_{3}$ (Glu out $)$ & 180 & $1.8 \times 10^{7} / \mathrm{M}$ & $10 \mu \mathrm{M}$ \\
\hline$K_{4}\left(\mathrm{H}^{+}\right.$out $)$ & 1500 & $10^{11} / \mathrm{M}$ & $15 \mathrm{~nm}$ \\
\hline$K_{5}$ (unbound open) & 7000 & 1600 & 4.375 \\
\hline$K_{6}($ bound open $)$ & 2500 & 5000 & 0.5 \\
\hline$K_{7}$ & 200 & 230 & 0.87 \\
\hline$K_{8}$ (Glu in) & 16.5 & $10^{5} / \mathrm{M}$ & $165 \mu \mathrm{M}$ \\
\hline$K_{9}\left(\mathrm{H}^{+}\right.$in $)$ & $10 \times 10^{4}$ & $10^{11} / \mathrm{M}$ & $100 \mathrm{~nm}$ \\
\hline$K_{10}\left(\mathrm{~K}^{+}\right.$in $)$ & $5 \times 10^{5}$ & $10^{8} / \mathrm{M}$ & $5 \mathrm{~mm}$ \\
\hline$K_{11}$ & 238 & 2000 & 0.119 \\
\hline
\end{tabular}




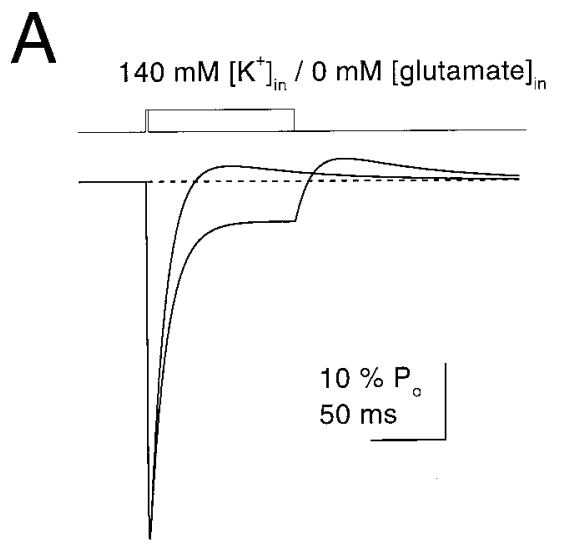

C

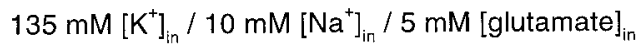

B

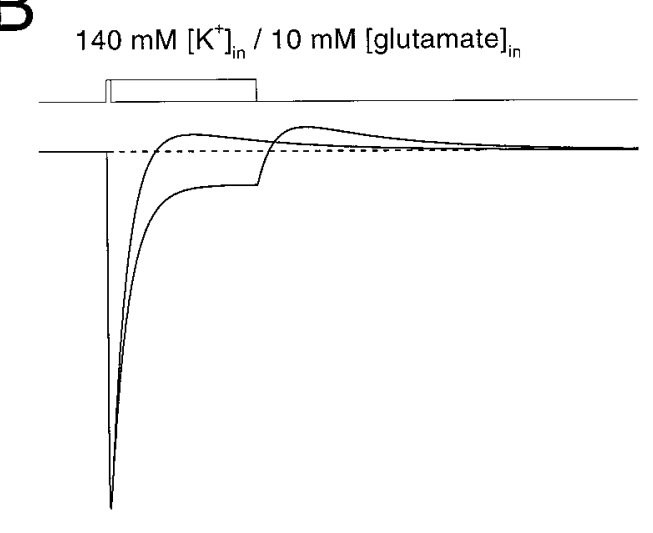

D $140 \mathrm{mM}\left[\mathrm{Na}^{+}\right]_{\text {in }} / 10 \mathrm{mM}$ [glutamate $]_{\text {in }}$

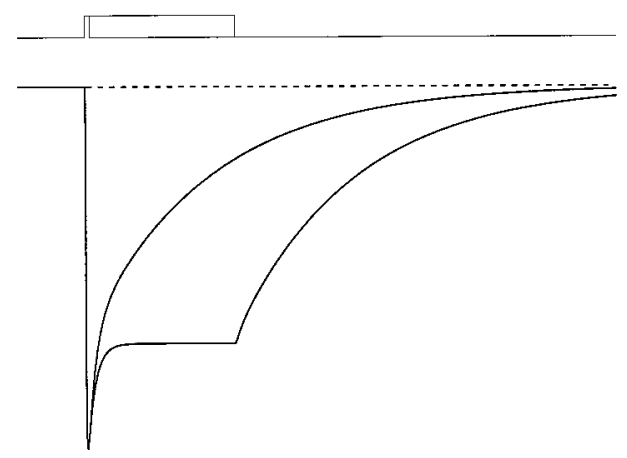

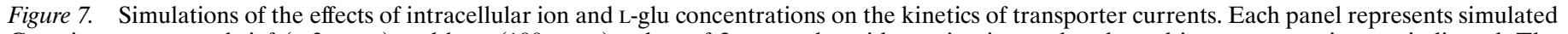

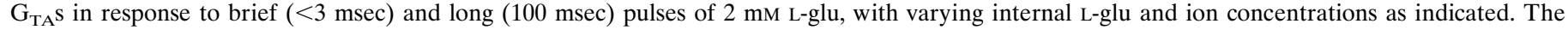

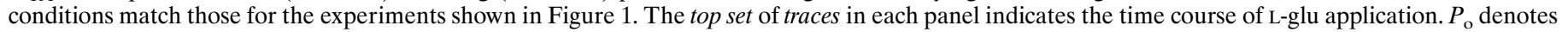

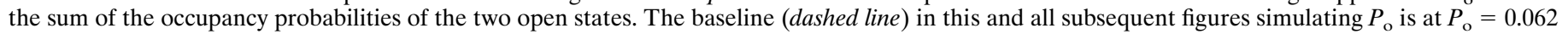
because of the conductance in the absence of agonist.

potentiation of the response caused by kainate in the model is attributable to the fact that kainate antagonizes the steady-state baseline current more effectively than it does the peak.

\section{The model predicts glutamate flux in addition to the anion conductance}

One aim of this study was to understand at a quantitative level the relationship between the $\mathrm{G}_{\mathrm{TA}}$ and the stoichiometrically coupled transport steps. Unfortunately, the coupled cationic charge movements corresponding to L-glu flux are too small to resolve in these studies; therefore, the kinetics of $\mathrm{G}_{\mathrm{TA}}$ and this component cannot be compared directly, although the hippocampal astrocyte transporter seems to exhibit a coupled current and an anion current with similar kinetics (Bergles and Jahr, 1997). To examine the relationship between glutamate flux and $G_{\text {TA }}$, we estimated the rate of internal L-glu accumulation by determining net flux between the states $\mathrm{HGN}^{2} \mathrm{~T}_{\mathrm{i}}$ and $\mathrm{HN}^{2} \mathrm{~T}_{\mathrm{i}}$ as a function of time. In conjunction, $\mathrm{G}_{\mathrm{TA}}$ was simulated by monitoring $P_{\mathrm{o}}$ under the same conditions. The predictions of the model of $\mathrm{G}_{\mathrm{TA}}$ (Fig. 9A,B, top) and net glutamate flux (bottom) versus time are shown in response to 2- and 100-msec-duration pulses of $2 \mathrm{~mm} \mathrm{L-glu.} \mathrm{The}$ simulation in Figure $9 A$ was performed with external $\left[\mathrm{Na}^{+}\right]$and internal $\left[\mathrm{K}^{+}\right]$of $140 \mathrm{~mm}$ and no $\mathrm{Na}^{+}$or L-glu inside. The addition of physiological concentrations of $\mathrm{Na}^{+}$and L-glu (10 mM) to the inside had a significant effect on the kinetics of the $\mathrm{G}_{\mathrm{TA}}$, as shown earlier, but also slowed the predicted net rate of L-glu accumula- tion (Fig. 9B). This inhibition of L-glu transport by internal $\mathrm{Na}^{+}$ was examined in more detail in Figure $9 C$. Here the net number of L-glu molecules transported for each transporter was determined for different duration pulses of L-glu by using the same two sets of ionic conditions as in Figure 9, $A$ and $B$. Under both conditions the probability of a molecule being transported increased steeply as a function of pulse duration over the time range during which the binding of L-glu and the $\mathrm{H}^{+}$occurs (durations $>250 \mu \mathrm{sec}$ ). The probability then approached but remained $<1$ for pulse durations briefer than $10 \mathrm{msec}$ (Fig. 9C). Lengthening L-glu applications beyond $60 \mathrm{msec}$ resulted in the accumulation of greater than one L-glu molecule per transporter. This can be understood by considering that, on binding, multiple cycles of transport can occur during the longer applications, the number of cycles determined by the steady-state turnover rates in $2 \mathrm{~mm} \mathrm{L-glu} \mathrm{(13.1} \mathrm{and} \mathrm{7.9/sec,} \mathrm{respectively,} \mathrm{for} 0$ and $10 \mathrm{mM} \mathrm{Na}^{+}$ conditions). These maximal turnover rates indicated by the model are similar to the turnover rate of 14.6/sec suggested for the glial glutamate transporter EAAT2 (Wadiche et al., 1995b). As is evident in Figure $9 C$, the effect of internal $\mathrm{Na}^{+}$and L-glu (compare filled circles with open circles) was to lower uniformly the probability of net transport at all durations. Another approach toward assessing the efficiency of transport is to determine the likelihood, given binding, that an L-glu molecule will be transported. This can be estimated by dividing the net transport rate by 


\section{A}

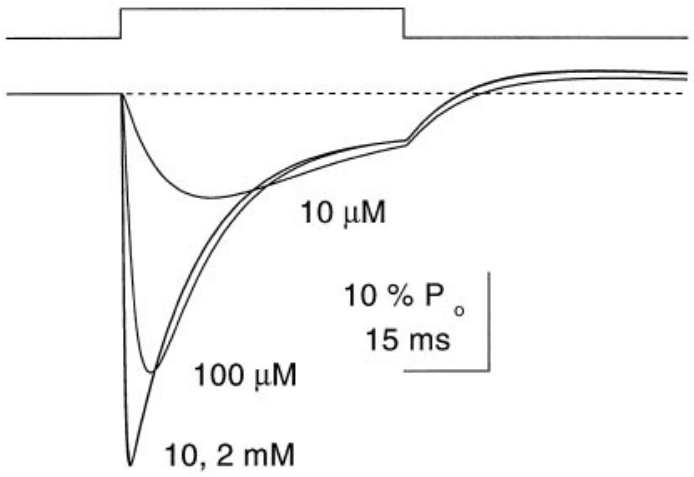

B

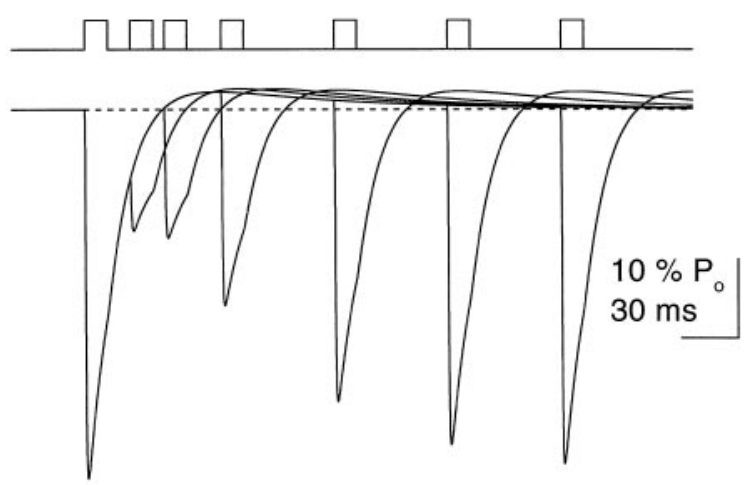

C

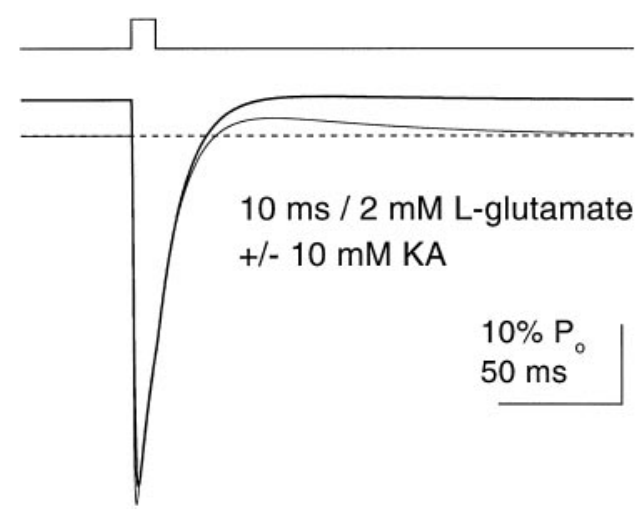

Figure 8. Simulations of the dose dependence, recovery, and kainate blockade experiments. $A$, Results from the model in response to $50 \mathrm{msec}$ steps into varying doses of L-glu. The conditions are the same as in Figure $4 A$. $B$, Simulations of pairs of $10 \mathrm{msec}$ steps of $2 \mathrm{~mm}$ L-glu delivered at different intervals to monitor the recovery. Conditions are the same as in Figure $5 A$. $C$, To simulate the effects of $10 \mathrm{~mm}$ kainate on the overshoot, we added an additional state to the model shown in Figure 6. This kainate-bound state was in fast equilibrium with the state $\mathrm{N}^{3} \mathrm{~T}_{\mathrm{o}}$ and had a $K_{\mathrm{D}}=1 \mathrm{mM}$, with a [kainate]-dependent binding rate of $10^{7} \mathrm{M} / \mathrm{sec}$ and a dissociation rate of $10^{4} / \mathrm{sec}$. Displayed are superimposed responses to 10 msec pulses of $2 \mathrm{~mm}$ L-glu delivered to the model in the continuous presence (darker line) and in the absence of $10 \mathrm{~mm}$ kainate. Conditions are the same as those in Figure $3 A$.

the forward flux into the bound-state $\mathrm{GN}^{3} \mathrm{~T}_{\mathrm{o}}$ at steady state under conditions in which there is no net efflux. With no $\mathrm{Na}^{+}$or L-glu inside, the model predicts that $74.6 \%$ of the molecules that bind are transported, whereas with $10 \mathrm{~mm} \mathrm{Na}^{+}$inside, this efficiency drops to $51.7 \%$. These calculations suggest that the Purkinje neuron glutamate transporter operates with a high capture effi-

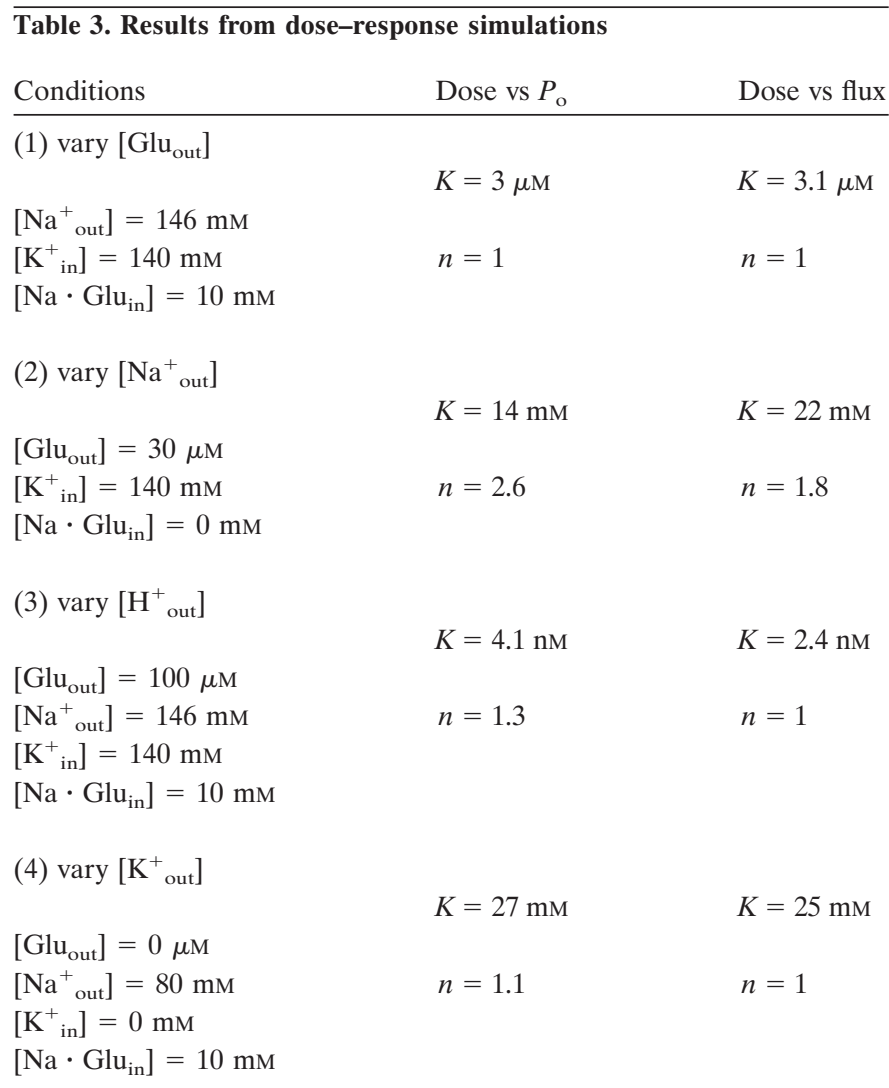

Dose dependencies for glutamate, $\mathrm{Na}^{+}, \mathrm{H}^{+}$, or $\mathrm{K}^{+}$ions were simulated for steadystate $P_{\mathrm{o}}$ or steady-state flux under the indicated conditions. An equation of the form:

$$
R=R_{\max } \cdot[\text { ion }]^{\mathrm{n}} /\left([\text { ion }]^{\mathrm{n}}+K^{\mathrm{n}}\right),
$$

was fit to simulated [ion] versus response relationships where $K$ and $n$ were allowed to vary, and $R_{\max }$ was fixed at the maximal response value. In all conditions $\mathrm{pH}_{\mathrm{in}}$ was set at 7.3; in all conditions except (3), $\mathrm{pH}_{\text {out }}$ was 7.4 ; and in all except (4), [ $\left.\mathrm{K}^{+}{ }_{\text {out }}\right]$ was set at $2.5 \mathrm{~mm}$.

ciency that may be modulated in the physiological range of internal $\mathrm{Na}^{+}$concentrations.

\section{Simulated glutamate and anion flux are proportional over a wide range of conditions}

Under certain conditions the transporter currents resulting from synaptic release can be recorded in individual glial cells or neurons (Mennerick and Zorumski, 1994; Bergles and Jahr, 1997; Bergles et al., 1997; Clark and Barbour, 1997; Otis et al., 1997). One advantage of recording synaptically elicited transporter currents is that, in principle, the measurements offer the possibility of determining how many glutamate molecules have been transported. These estimates require knowledge of the number of charges moving across the membrane per transport cycle. For recombinant transporters this can be measured at steady state by monitoring the accumulation of radiolabeled L-glu into voltageclamped Xenopus oocytes expressing glutamate transporter mRNA (Wadiche et al., 1995a,b; Zerangue and Kavanaugh, 1996; Otis et al., 1997). However, steady-state estimates may be misleading, because synaptic responses result from transient elevations in L-glu concentrations. Depending on the mechanism of coupling between the $\mathrm{G}_{\mathrm{TA}}$ and glutamate translocation, the ratio of charge transfer to L-glu flux may not be constant.

To test whether the present model predicted the same chargeto-flux ratio in pre-steady-state as well as steady-state conditions, 
A
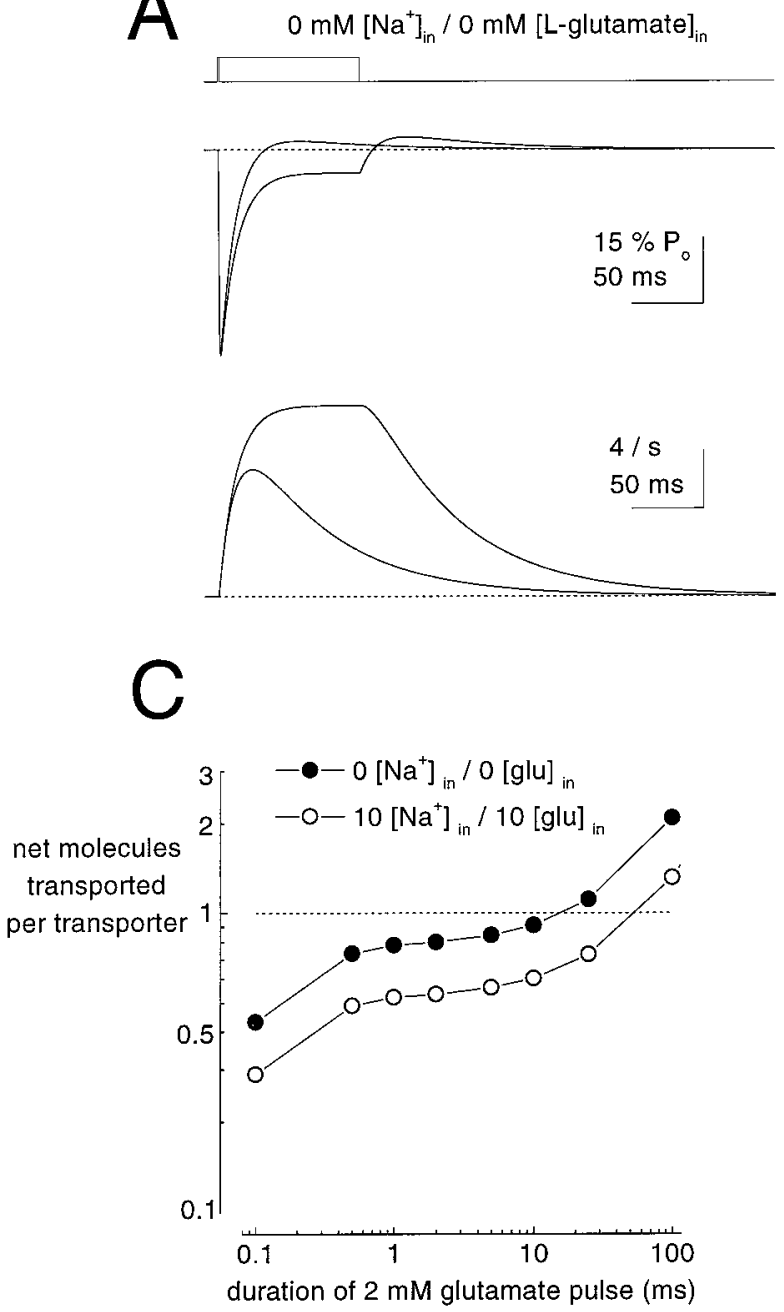

$\mathrm{B}$ $10 \mathrm{mM}\left[\mathrm{Na}^{+}\right]_{\text {in }} / 10 \mathrm{mM}[\text { L-glutamate }]_{\text {in }}$
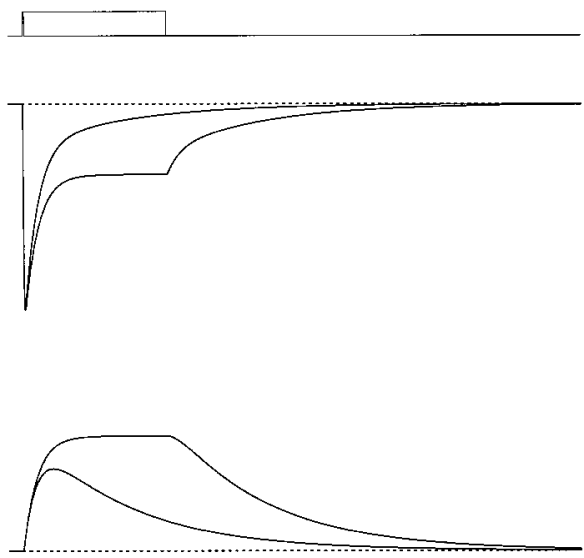

$\mathrm{D}$

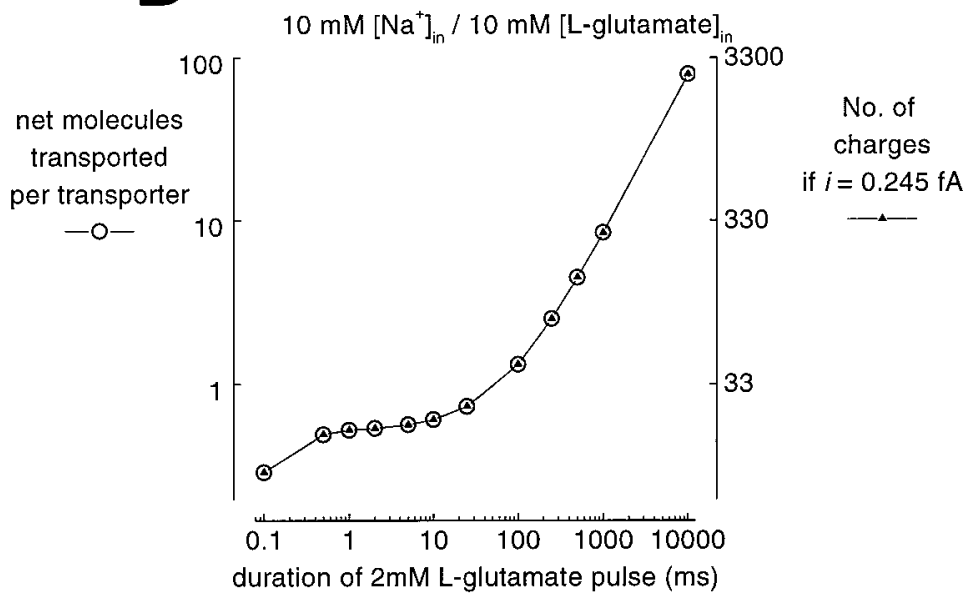

Figure 9. Simulations of $\mathrm{G}_{\mathrm{TA}}$ and of the amount of $\mathrm{L}$-glu uptake. A, Simulated $\mathrm{G}_{\mathrm{TA}}$ (middle set of traces) and net flux of L-glu (bottom set of traces) to the intracellular compartment in response to a 1- and 100-msec-duration pulse of $2 \mathrm{mM} \mathrm{L-glu.} \mathrm{The} \mathrm{top} \mathrm{set} \mathrm{of} \mathrm{traces} \mathrm{indicates} \mathrm{the} \mathrm{time} \mathrm{course} \mathrm{of} \mathrm{L-glu}$ presentation. The simulation was performed with no $\mathrm{Na}^{+}$or $\mathrm{L}$-glu in the intracellular compartment. $B$, Similar simulation as in $A$ but with 10 mM $\left[\mathrm{Na}-\mathrm{Glu}_{\mathrm{in}}\right]$. Note the slowing of the $\mathrm{G}_{\mathrm{TA}}$, as in Figures 1 and 7, and the reduced net flux of L-glu. $C$, The net number of L-glu molecules transported per transporter as a function of the duration of a $2 \mathrm{mM} \mathrm{L}$-glu pulse. The simulation has been performed for the two different internal solutions $\left(0\right.$ [Na-Glu $\left.{ }_{\text {out }}\right]$, - $10 \mathrm{~mm}\left[\mathrm{Na}-\mathrm{Glu}_{\text {out }}\right], \bigcirc$ ) shown in $A$ and $B$. The cases in which the predicted number of transported molecules is $<1$ can be considered as the probability, per transporter, of net accumulation of an L-glu molecule. Note that both axes are on a logarithmic scale. $D$, Shown on a log-log scale, the predicted flux of L-glu $(\bigcirc)$ and charge $(\boldsymbol{\Lambda})$ per transporter as a function of the duration of a $2 \mathrm{~mm}$ pulse of L-glu. To convert $P_{\mathrm{o}}$ to charge flux, we arbitrarily chose a single channel current of $0.245 \mathrm{fA}$.

we simulated net L-glu flux and the $\mathrm{G}_{\mathrm{TA}}$ for a range of durations of $2 \mathrm{~mm}$ L-glu pulses. A single channel current amplitude of 0.245 fA was assigned arbitrarily to both conducting states to yield a charge-to-flux ratio previously determined for the Purkinje neuron-specific glutamate transporter EAAT4 (Otis et al., 1997). The number of L-glu molecules transported by each transporter (Fig. 9D, open circles) and the number of elementary charges per cycle (Fig. 9D, filled triangles) are plotted versus the duration of an L-glu pulse in Figure 9D. It is clear that charge transfer and L-glu flux are directly proportional over the range of durations between $0.1 \mathrm{msec}$ and $10 \mathrm{sec}$. In related simulations, charge-to-flux ratios predicted by the model are also independent of L-glu concentration over the micromolar to millimolar range (data not shown). Thus, the model supports the proposal that charge transfer through the glutamate transporter during synaptic signaling can be used to estimate the number of L-glu molecules transported.

\section{DISCUSSION}

In the present study, experimental measurements of the dynamics of the anion current mediated by the Purkinje neuron transporter have been used to construct a cyclic kinetic model linking the $\mathrm{G}_{\mathrm{TA}}$ to the transport cycle. It is hoped that this model will be useful for several reasons. First, it may prompt specific experiments aimed at determining the mechanistic link between the $\mathrm{G}_{\mathrm{TA}}$ and the transport cycle. Second, transporter kinetic properties can be incorporated into more detailed simulations of transmitter diffusion at excitatory synapses on Purkinje neurons. Third, the model provides justification for a simple method of calibrating the amount of glutamate uptake occurring at synapses in situ.

As with most models, it is almost certain that more complicated models also could account for the data. It also should be kept in mind that some aspects of the model have been determined arbitrarily. For instance, the binding order of L-glu and the $\mathrm{H}^{+}$is 
not known, and in fact it has been suggested that, rather than the cotransport of a proton, a hydroxyl anion is countertransported (Billups et al., 1996). We chose to incorporate a proton as the $\mathrm{pH}$-changing ion on the basis of data demonstrating that transport of L-cysteine, an amino acid with neutral charge at physiological $\mathrm{pH}$, is not accompanied by intracellular acidification (Zerangue and Kavanaugh, 1996). With regard to binding order, the extremely low concentrations of $\mathrm{H}^{+}$made it difficult to simulate rapid activation of the $\mathrm{G}_{\mathrm{TA}}$ with a model in which $\mathrm{H}^{+}$binds before L-glu. Controversy also exists regarding the number of $\mathrm{Na}^{+}$ions coupled to the transport cycle. For this reason a similar model was constructed with two $\mathrm{Na}^{+}$binding sites instead of three (Bouvier et al., 1992). Using a slightly different set of rates, this model also represented all of the major features of the data (not shown). It is encouraging, however, that a simple cyclic model incorporating all ion binding steps is able to simulate accurately the dynamics of the $\mathrm{G}_{\mathrm{TA}}$ under different conditions while also conforming to thermodynamic principles regarding electrochemical flux.

\section{Implications for the climbing fiber-elicited synaptic transporter current}

Recently, the glutamate transporter EAAT4 was localized at the electron microscopic level and shown to be present on Purkinje neuron dendrites surrounding postsynaptic densities (Furuta et al., 1997; Tanaka et al., 1997a; Dehnes et al., 1998). There is disagreement regarding the presence of other glutamate transporters: some laboratories report that EAAC1 is also present in Purkinje neurons (Kanai et al., 1995; Furtura et al., 1997) (but see Tanaka et al., 1997a). In light of the localization of EAAT4 near postsynaptic receptors, several kinetic properties of the Purkinje neuron glutamate transporter model are worth considering. The binding rate of $1.8 \times 10^{7} \mathrm{M} / \mathrm{sec}$ in this model is very similar to that suggested for the Purkinje neuron AMPA-type glutamate receptor $\left(1.4 \times 10^{7} \mathrm{M} / \mathrm{sec}\right.$; Haüsser and Roth, 1997), raising the possibility that binding to the receptors and transporters could occur simultaneously (Diamond and Jahr, 1997). However, climbing fiber-elicited transporter currents rise slowly as compared with the EPSC (2.6 vs $0.3 \mathrm{msec}$ ) (Otis et al., 1997), suggesting that some transporters on the Purkinje neuron are activated either with a delay or by a lower concentration of L-glu or, most likely, by some combination of both. Realistic models incorporating L-glu diffusion and accurate locations, densities, and binding properties of glutamate receptors and transporters will be required to understand the time course of the synaptic transporter current in detail.

The turnover time estimated by the model is very similar to that proposed for the glial transporter EAAT2 (Wadiche et al., $1995 \mathrm{~b}$ ). This minimal turnover time of $\sim 75 \mathrm{msec}$ is considerably slower than the range of estimates of L-glu lifetime in synapses (Clements et al., 1992; Otis et al., 1996). Therefore, multiple cycles of transport would not be expected to occur in response to a single climbing fiber input. In a previous study it was estimated that after release from the climbing fiber terminals $\sim 20 \%$ of the transmitter is transported into the postsynaptic neuron (Otis et al., 1997). This slow turnover time and the imperfect efficiency $(50-75 \%)$ of the Purkinje neuron transporter may account for this small fraction despite the "privileged" localization of the neuronal transporters.

Blocking glutamate transporters at the climbing fiber synapse slows the EPSC (Barbour et al., 1994). Recently, Takahashi et al. (1996) have suggested that selective inhibition of postsynaptic transporters, as opposed to those in the Bergmann glia (Bergles et al., 1997; Clark and Barbour, 1997), also slows the EPSC. In this light, one role for neuronal glutamate transporters localized near postsynaptic densities could be to limit the crosstalk between closely spaced active release sites (Takahashi et al., 1995; Otis et al., 1996) to ensure that each release site is maximally effective.

Given that clearance from the synaptic cleft is much faster than the transporter cycling rate, it seems that the most effective mechanism for potentiation of Purkinje neuron glutamate transporter currents (Kataoka et al., 1997) would not be to increase the turnover rate. Rather, the modulation may involve an increase in the number of functional transporters after phosphorylation (Casado et al., 1993) or recruitment of transporters from intracellular compartments similar to that reported for the GABA transporter (Quick et al., 1997). Interestingly, immunocytochemical data suggest the possibility of a large cytoplasmic pool of EAAT4 glutamate transporters (Tanaka et al., 1997a; Dehnes et al., 1998). The high efficiency of transport after binding (probability of $50-75 \%$, depending on internal $\mathrm{Na}^{+}$) makes it more likely that a moderate increase in the number of transporters would result in an increase in L-glu clearance.

The apparent dependence of the transporter current on the intracellular $\mathrm{Na}^{+}$concentration was similar to that reported by Barbour et al. (1991). The effects of this $\mathrm{Na}^{+}$dependence on L-glu transport as predicted by the model were striking; maximal turnover rates dropped by $50 \%$ in a physiological range of internal $\mathrm{Na}^{+}$concentration. This high affinity for internal $\mathrm{Na}^{+}$relative to external $\mathrm{Na}^{+}$may be a key determinant of the ability of this transporter to undergo reversed uptake during ischemic insult. Further study will be required to determine whether this is a common feature of other glutamate transporters.

\section{REFERENCES}

Arriza JL, Fairman WA, Wadiche JL, Murdoch GH, Kavanaugh MP, Amara SG (1994) Functional comparisons of three glutamate transporter subtypes cloned from human motor cortex. J Neurosci 14:5559-5569.

Barbour B, Brew H, Attwell D (1991) Electrogenic uptake of glutamate and aspartate into glial cells isolated from the salamander (Ambystoma) retina. J Physiol (Lond) 436:169-193.

Barbour B, Keller BU, Llano I, Marty A (1994) Prolonged presence of glutamate during excitatory synaptic transmission to cerebellar Purkinje cells. Neuron 12:1331-1343.

Bergles DE, Jahr CE (1997) Synaptic activation of glutamate transporters in hippocampal astrocytes. Neuron 19:1297-1308.

Bergles DE, Dzubay JA, Jahr CE (1997) Glutamate transporter currents in Bergmann glial cells follow the time course of extrasynaptic glutamate. Proc Natl Acad Sci USA 94:14821-14825.

Billups B, Rossi D, Attwell D (1996) Anion conductance behavior of the glutamate uptake carrier in salamander retinal cells. J Neurosci 16:6722-6731.

Bouvier M, Szatkowski M, Amato A, Attwell D (1992) The glial cell glutamate uptake carrier countertransports $\mathrm{pH}$-changing anions. $\mathrm{Na}$ ture 360:471-474.

Cammack JN, Rakhilin SV, Schwartz EA (1994) A GABA transporter operates asymmetrically and with variable stoichiometry. Neuron 13:949-960.

Casado M, Bendahan A, Zafra F, Danbolt NC, Aragón C, Giménez C, Kanner BI (1993) Phosphorylation and modulation of brain glutamate transporters by protein kinase C. J Biol Chem 268:27313-27317.

Clark BA, Barbour B (1997) Currents evoked in Bergmann glial cells by parallel fibre stimulation in rat cerebellar slices. J Physiol (Lond) 502:335-350.

Clements JD, Lester RA, Tong G, Jahr CE, Westbrook GL (1992) The time course of glutamate in the synaptic cleft. Science 258:1498-1501.

Dehnes Y, Chaudhry FA, Ullensvang K, Lehre KP, Storm-Mathisen J, Danbolt NC (1998) The glutamate transporter EAAT4 in rat cerebellar Purkinje cells: a glutamate-gated chloride channel concentrated 
near the synapse in parts of the dendritic membrane facing astroglia. J Neurosci 18:3606-3619.

Diamond JS, Jahr CE (1997) Transporters buffer synaptically released glutamate on a millisecond time scale. J Neurosci 17:4672-4687.

Eliasof S, Jahr CE (1996) Retinal glial cell glutamate transporter is coupled to an anionic conductance. Proc Natl Acad Sci USA 93:4153-4158.

Fairman WA, Vandenberg RJ, Arriza JL, Kavanaugh MP, Amara SG (1995) An excitatory amino-acid transporter with properties of a ligand-gated chloride channel. Nature 375:599-603.

Furuta A, Martin LJ, Lin C-LG, Dykes-Hoberg M, Rothstein JD (1997) Cellular and synaptic localization of the neuronal glutamate transporters excitatory amino acid transporter 3 and 4 . Neuroscience 81:1031-1042.

Galli A, De-Felice LJ, Duke BJ, Moore KR, Blakely RD (1995) Sodium-dependent norepinephrine-induced currents in norepinephrine transporter-transfected HEK-293 cells blocked by cocaine and antidepressants. J Exp Biol 198:2197-2212.

Haüsser M, Roth A (1997) Dendritic and somatic glutamate receptor channels in rat cerebellar Purkinje cells. J Physiol (Lond) 501:77-95.

Kanai Y, Hediger MA (1992) Primary structure and functional characterization of a high-affinity glutamate transporter. Nature 360:467-471.

Kanai Y, Bhide PG, DiFiglia M, Hediger MA (1995) Neuronal highaffinity glutamate transport in the rat central nervous system. NeuroReport 6:2357-2362.

Kanner BI, Bendahan A (1982) Binding order of substrates to the sodium and potassium ion-coupled glutamic acid transporter from rat brain. Biochemistry 21:6327-6330.

Kanner BI, Sharon I (1978) Active transport of glutamate by membrane vesicles isolated from rat brain. Biochemistry 17:3949-3953.

Kataoka Y, Morii H, Watanabe Y, Ohmori H (1997) A postsynaptic excitatory amino acid transporter with chloride conductance functionally regulated by neuronal activity in cerebellar Purkinje cells. J Neurosci 17:7017-7024.

Kavanaugh MP, Bendahan A, Zerangue N, Zhang Y, Kanner BI (1997) Mutation of an amino acid residue influencing potassium coupling in the glutamate transporter GLT-1 induces obligate exchange. J Biol Chem 272:1703-1708.

Lin CL, Bristol LA, Jin L, Dykes-Hoberg M, Crawford T, Clawson L, Rothstein JD (1998) Aberrant RNA processing in a neurodegenerative disease: the cause for absent EAAT2, a glutamate transporter, in amyotrophic lateral sclerosis. Neuron 20:589-602.

Mager S, Min C, Henry DJ, Chavkin C, Hoffman BJ, Davidson N, Lester HA (1994) Conducting states of a mammalian serotonin transporter. Neuron 12:845-859.
Mennerick S, Zorumski CF (1994) Glial contribution to excitatory transmission in cultured hippocampal cells. Nature 368:59-62.

Otis TS, Wu YC, Trussell LO (1996) Delayed clearance of transmitter and the role of glutamate uptake at a synapse with multiple release sites. J Neurosci 16:1633-1643.

Otis TS, Kavanaugh MP, Jahr CE (1997) Postsynaptic glutamate transport at the climbing fiber-Purkinje cell synapse. Science 277:1515-1518.

Quick MW, Corey JL, Davidson N, Lester HA (1997) Second messengers, trafficking-related proteins, and amino-acid residues that contribute to the functional regulation of the rat brain GABA transporter GAT1. J Neurosci 17:2967-2979.

Sonders MS, Zhu SJ, Zahniser NR, Kavanaugh MP, Amara SG (1997) Multiple ionic conductances of the human dopamine transporter: the actions of dopamine and psychostimulants. J Neurosci 17:960-974.

Stallcup W B, Bulloch K, Baetge EE (1979) Coupled transport of glutamate and sodium in a cerebellar nerve cell line. J Neurochem 32:57-65.

Szatkowski M, Barbour B, Attwell D (1990) Nonvesicular release of glutamate from glial cells by reversed electrogenic glutamate uptake. Nature 348:443-446.

Takahashi M, Kovalchuk Y, Attwell D (1995) Pre- and postsynaptic determinants of EPSC waveform at cerebellar climbing fiber and parallel fiber to Purkinje cell synapses. J Neurosci 15:5693-5702.

Takahashi M, Sarantis M, Attwell D (1996) Postsynaptic glutamate uptake in rat cerebellar Purkinje cells. J Physiol (Lond) 497:523-530.

Tanaka J, Ichikawa R, Watanabe M, Tanaka K, Inoue Y (1997a) Extrajunctional localization of glutamate transporter EAAT4 at excitatory Purkinje cell synapses. NeuroReport 8:2461-2464.

Tanaka K, Watase K, Manabe T, Yamada K, Watanabe M, Takahashi K, Iwama $\mathrm{H}$, Nishikawa $\mathrm{T}$, Ichihara $\mathrm{N}$, Kichuchi $\mathrm{T}$, Okuyama $\mathrm{S}, \mathrm{Ka}-$ washima N, Hori S, Takimoto M, Wada K (1997b) Epilepsy and exacerbation of brain injury in mice lacking the glutamate transporter GLT-1. Science 276:1699-1702.

Vandenberg RJ, Arriza JL, Amara SG, Kavanaugh MP (1995) Constitutive ion fluxes and substrate binding domains of human glutamate transporters. J Biol Chem 270:17668-17671.

Wadiche JI, Kavanaugh MP (1998) Macroscopic and microscopic properties of a cloned glutamate transporter/chloride channel. J Neurosci, in press.

Wadiche JI, Amara SG, Kavanaugh MP (1995a) Ion fluxes associated with excitatory amino acid transport. Neuron 15:721-728.

Wadiche JI, Arriza JL, Amara SG, Kavanaugh MP (1995b) Kinetics of a human glutamate transporter. Neuron 14:1019-1027.

Zerangue N, Kavanaugh MP (1996) Flux coupling in a neuronal glutamate transporter. Nature 383:634-637. 